Теория и история государства и права

УДК 340.1

DOI https://doi.org/10.17308/vsu.proc.law.2020.3/2974

\title{
ТИПОЛОГИЯ СРЕДСТВ И ПРИЕМОВ ПРАВОТВОРЧЕСКОЙ ТЕХНИКИ
}

\author{
Е. Н. Швед \\ Национальный иентр законодательства \\ и правовых исследований Республики Беларусь \\ Поступила в редакцию 22 октября 2019 г.
}

\begin{abstract}
Аннотация: в статье на основе авторских взглядов на понятия "юридическая техника", "средства юридической техники", "приелы юридической техники" проводится типология средств и приелов основного типа (вида) юридической техники - правотворческой техники. Типологический метод выбран "стержневыл" приелом познания объекта исследования, поскольку, по лнению автора, осуществить классификацию средств и приелов правотворческой техники, т. е. указать одну единственную группу их существенных признаков и свойств, не представляется возложныл.

Ключевые слова: юридическая техника, видь юридической техники, состав юридической техники, правотворческая техника, средства правотворческой техники, приелы правотворческой техники, типология.
\end{abstract}

\begin{abstract}
: in the article, on the basis of the author's views on the concepts of "legal technique", "means of legal technology", "methods of legal technology", a typology of the means and methods of the main type of legal technology-law-making technology is carried out. The typological method was chosen as the "core" method of cognition of the object of study, since, according to the author, it is not possible to classify the means and techniques of law-making equipment, that is, to indicate one single group of their essential features and properties.

Key words: legal technology, types of legal equipment, composition of legal technology, law making technique, law-making equipment, law-making techniques, typology.
\end{abstract}

Одна из нерешенных научных проблем в области юридической техники - проблема определения ее состава, т. е. набора того юридического инструментария, с помощью которого обеспечивается достижение целей юридической деятельности. В науке и практике накоплено множество средств, приемов юридической техники, но, к сожалению, отсутствует единство в их использовании и применении. Авторы, как правило, либо просто перечисляют хаотичный «набор» средств и приемов юридической техники, либо представляют их классификацию, не определив при этом четкого основания (критерия) для этого. Полагаем, пришло время найти наиболее устойчивые сочетания свойств и признаков средств и приемов юридической техники.

Ввиду разносторонности юридической техники и сложностей в выработке единых видов средств и приемов, ее составляющих, считаем целесообразным рассматривать средства и приемы юридической техники при-

(C) Швед Е. Н., 2020 


\section{Вестник ВГУ. Серия: Право}

менительно к каждому из типов (видов) юридической техники. Автором настоящей статьи ранее были выделены четыре основных вида юридической техники: правотворческая техника, техника реализации права, техника систематизации права, техника интерпретации права ${ }^{1}$.

Полагаем, основной и наиболее ответственной формой правовой деятельности является правотворчество, поскольку именно нормативные правовые акты являются выражением и результатом установления (санкционирования) правовых норм. Высока роль издания нормативных правовых актов в управленческой деятельности: посредством их издания формируется самостоятельная правовая форма управленческой деятельности - правоустановительная ${ }^{2}$. В настоящее время по мере усложнения процессов общественного развития на передний план выдвигаются проблемы правотворчества, а значит, считаем важным из инструментария различных видов юридической техники, в первую очередь, «разобраться» со средствами и приемами правотворческой техники.

Классификации средств и приемов правотворческой техники могут быть различными. Например, один из критериев классификации - вид нормативного правового акта. То есть можно вести речь о средствах и приемах правотворческой техники, используемых при подготовке законов; средствах и приемах, используемых при подготовке нормативных правовых актов Президента Республики Беларусь и т. д. Еще одним критерием классификации средств и приемов правотворческой техники является субъект, использующий их для подготовки проекта нормативного правового акта. В этом случае можно вести речь о средствах и приемах, используемых Президентом Республики Беларусь, Советом Министров Республики Беларусь, министерствами, иными республиканскими органами государственного управления и т. д.

Действительно, в разработке каждого из видов нормативных правоm вых актов имеются свои особенности. Тем не менее считаем возможным 글 выделить общие, используемые для подготовки проектов различных нор¿े мативных правовых актов, средства и приемы правотворческой техники.

Основным «инструментом» нахождения и обоснования существенных, общих, стабильных и устойчивых признаков и свойств имеющихся средств и приемов правотворческой техники, их группировки, по нашему мнению, является типологический метод. Именно типология, будучи конкретной модификацией решения задачи синтеза, призвана установить зависимость и взаимосвязь между основными признаками, а также между ними и окружающей средой ${ }^{3}$. Рассмотрим типы средств и приемов правотворческой техники.

${ }^{1}$ См.: Швед Е. Н. Виды юридической техники // Вестник Сибир. ин-та бизнеса и информ. технологий. 2019. № 1. С. 85-88.

${ }^{2}$ См.: Старилов Ю. Н. Административное право : в 2 ч. Ч. 2 : Книга вторая : Формы и методы управленческих действий. Правовые акты управления. Административный договор. Административная юстиция. Воронеж, 2001. С. 20.

${ }^{3}$ См.: Сильченко Н. В. Научные основы типологии нормативно-правовых актов : дис. ... канд. юрид. наук. М., 1981. С. 15. 
Средства правотворческой техники. На наш взгляд, во всей совокупности средств правотворческой техники можно выделить два основных типа:

1) средства, используемые при создании текста нормативного правового акта;

2) средства, используемые при выполнении иной работы, составляющей правотворческий процесс.

Средства, используелье при создании текста норлативного правового акта. Подготовка проекта нормативного правового акта включает в себя наиважнейшую для правотворческой техники работу создание текста проекта нормативного правового акта. Именно текст и, соответственно, правовые нормы, изложенные в структурных частях нормативного правового акта, являются основными объектами правотворческой техники. Текст (лат. textum - связь, соединение) в лингвистике - это «внутренне организованная последовательность отрезков письменного произведения или записанной либо звучащей речи, относительно законченной по своему содержанию и строению» ${ }^{4}$ Текст же права, как отмечает А. А. Деревнин, представляет собой внешнее выражение права или ту форму, в которую при помощи средств и приемов правотворческой техники облекаются нормы права ${ }^{5}$.

Средства правотворческой техники предназначены для оформления нормативного правового акта, придания ему окончательного готового к «употреблению» варианта. Здесь приобретает особое значение баланс между формой нормативного правового акта и его содержанием. В связи с этим можно вести речь о формальных и содержательных средствах правотворческой техники.

Форлальныли средствами правотворческой техники, или средствами обеспечения точности формы нормативного правового акта, являются, например, реквизиты. Обязательными реквизитами нормативных правовых актов являются: вид; дата, место принятия (издания); регистрационный номер; название; должность, подпись, инициалы (инициал собственного имени) и фамилия должностного лица (лиц), уполномоченного подписывать нормативный правовой акт; гриф утверждения, гриф приложения, ограничительный гриф «Для служебного пользования», гриф секретности в случаях и порядке, предусмотренных Законом Республики Беларусь от 17 июля 2018 г. «О нормативных правовых актах» и иными актами законодательства. В законах дополнительно указываются обязательные реквизиты «Принят Палатой представителей», «Одобрен Советом Республики»

${ }^{4}$ Ожегов С. И., Шведова Н. Ю. Толковый словарь русского языка : 80000 слов и фрразеологических выражений. 4-е изд., доп. М., 2006. С. 791.

${ }^{5}$ См.: Деревнин А. А. Правотворческая техника как инструмент создания текста права // Акад. юрид. журнал. 2000. № 1. С. 27-30.

${ }^{6} \mathrm{O}$ нормативных правовых актах : закон Республики Беларусь от 17 июля 2018 г. № 130-3 // Национальный правовой интернет-портал Республики Беларусь. URL: http://pravo.by/document/?guid=12551\&p0=H11800130\&p1=1 (дата обращения: 21.10.2019). 


\section{Вестник ВГУ. Серия: Право}

Содержательные средства правотворческой техники, или средства обеспечения точности содержания правового акта, также являются инструментом создания текста проекта нормативного правового акта. Необходимым средством правотворческой техники, входящим в эту группу, является язык. В юридической науке язык закона (язык правотворчества, язык законодательства, язык права, правовой язык) традиционно считается особой разновидностью литературного стиля или особого стиля литературной речи. Учеными рассматриваются исторические аспекты его становления и развития, связи с иными компонентами юридической техники. Особое признание в этих вопросах получили исследования Л. М. Бойко, Н. А. Власенко, И. Н. Грязина, Т. В. Губаевой, Н. Ф. Ковкель, А. С. Пиголкина, В. М. Савицкого, Ю. А. Тихомирова, А. А. Ушакова и других ученых. Язык - одно из важнейших средств всей юридической техники, поскольку является «инструментом, направленным на регулирование общественных отношений, или своеобразным строительным материалом» ${ }^{7}$, с помощью которого создается право.

Проблемы исследования языка права имеют прямую связь с понятием «законодательный стиль». Как отмечает С. С. Алексеев, «главное, что определяет стиль нормативных актов, состоит в том, чтобы обеспечить сочетание, с одной стороны, доступности и убедительности нормативных документов, а с другой - их точности, определенности и высокой юридической культуры» ${ }^{8}$. Стиль нормативных правовых актов концентрирует воедино и использование языка права, и применение требований современного литературного языка.

Еще одним средством правотворческой техники являются правовые понятия. Понятия представляют собой форму мышления, отражающую существенные свойства, связи и отношения предметов и явлений в их ๓ противоречии и развитии; мысль или систему мыслей, обобщающую, 을 выделяющую предметы некоторого класса по определенным общим и в совокупности специфическим для них признакам 9 . Правовые понятия составляют своего рода основу для правовых норм, и, как отмечает Д. А. Керимов, «важно правильно отобрать те понятия, которые наиболее адекватны целям правового регулирования соответствующих обществен-

100 ных отношений» ${ }^{10}$.

Тесная связь языкового материала со средствами правотворческой техники находит свое проявление в выработке юридической терлиноло-

7 Чинарян E. O. Становление и развитие законодательной техники в дореволюционной России (историко-теоретическое исследование) : дис. ... канд. юрид. наук. М., 2009. С. 14.

${ }^{8}$ Алексеев С. С. Общая теория права : в 2 т. М., 1982. Т. 2. С. 285.

${ }^{9}$ См.: Дышеков М. В., Шогениуков Р. С. Правовые понятия, термины и их применения в региональном проектировании законов // Право и государство : теория и практика. 2017. № 3. С. 45-51.

${ }^{10}$ Керилов Д. А. Законодательная техника : науч.-метод. и учеб. пособие. М., 2000. C. 49 . 
гии. Под термином понимается «слово (или группа логически взаимосвязанных слов), выражающее строго определенное понятие» ${ }^{11}$. Полагаем, именно с помощью терминов можно достигнуть точности в формулировании нормативных правовых актов. Можно сказать, что юридическая терминология является «начальным звеном» при юридическом выражении воли законодателя. С. Н. Болдырев полагает, что правовая терминология - это не только техническая конструкция, но и та материя, которая обусловливает смысл, содержание, предназначение принимаемых нормативных правовых актов ${ }^{12}$. Юридические термины, как и правовые понятия, - средства правотворческой техники, необходимые для компактности изложения текста нормативного правового акта и в то же время для полного и объективно правильного отражения действительности этого текста.

Полагаем, что перечисленные выше средства правотворческой техники (язык, стиль, терминологию, понятия) можно условно объединить в единую группу - языковые (лингвистические) средства, поскольку основное назначение каждого из них - выразить содержание норм права или «помочь» создать текст нормативного правового акта. В эту же группу языковых средств мы можем отнести и иные средства выражения языка - речевые клише, языковые символы, аббревиатуры, предложения, цифры, фрразеологизмы или устойчивые сочетания слов (например, «если иное не предусмотрено...», «в порядке, установленном...», «ввести в действие...."13) и др.

Для создания текста нормативного правового акта используется и группа средств правотворческой техники, которую мы назовем техническили (инструлентальнылии) средствали. В данном случае речь идет о колпьютерах, используемых в процессе написания текста проекта нормативного правового акта, офбисной технике (принтеры, сканеры и т. д.), бумаге и т. д. Эти средства правотворческой техники «оказывают техническую помощь» в выработке содержания правового акта и «придания ему формы конкретного материального носителя» ${ }^{14}$.

Средства, используелье при выполнении иной работы, составляющей правотворческий процесс. Данный тип средств правотворческой техники выделен нами для отражения необходимости использования инструментария юридической техники на последующих этапах правотворчества, когда текст проекта нормативного правового акта уже «готов к использованию».

${ }^{11}$ Красавчиков О. А. Ученые труды : в 3 т. Свердловск, 1961. Т. 6 : Советская наука гражданского права (понятие, предмет, состав и система). С. 124.

${ }^{12}$ См.: Болдыцев C. Н. Некоторые проблемы использования потенциала юридической техники // Юристъ-Правоведъ. 2011. № 1. С. 13-18.

13 Законодательная техника : науч.-практ. пособие / Л. Ф. Апт [и др.]. М., 2000. C. 149 .

${ }^{14}$ Радаева С. В. Юридическая техника как условие повышения эфрфективности правосудия : дис. ... канд. юрид. наук. Саратов, 2011. С. 14. 


\section{Вестник ВГУ. Серия: Право}

Важнейшую группу средств правотворческой техники в осуществлении дальнейшей работы с проектом нормативного правового акта составляют програллино-технологические средства. Среди них: средства компьютерных телекоммуникаций; сайты сети «Интернет»; государственные информационные ресурсы и системы и т. д. Данная группа средств правотворческой техники связана с все более широким применением в различных сфрерах государственной жизни информационно-коммуникационных технологий, ведь в современных условиях информационное общество диктует новые стандарты, ожидая от государства простого, комфортного, быстрого и эффрективного взаимодействия его органов с гражданами.

В настоящее время в Республике Беларусь программно-технологические средства правотворческой техники активно используются практически на всех стадиях нормотворческого процесса. Так, на стадии публичного обсуждения нормативных правовых актов программно-технологическими средствами правотворческой техники будут являться, например, сайт "Правовой фборул Беларуси" и банк данныхх "Проекты законов" (әлектронная версия). Обязательная юридическая экспертиза нормативных правовых актов и включение их в Национальный реестр правовых актов Республики Беларусь (далее - НРПА) сопровождаются использованием автолатизированной инфорлационной системы, обеспечивающей форлирование НРПА, в части взаимодействия Национального центра правовой информации Республики Беларусь, главных управлений юстиции областных исполнительных комитетов и местных советов депутатов, исполнительных и распорядительных органов базового территориального уровня при включении в НРПА нормативных правовых актов указанных нормотворческих органов. Автоматизирована в Республике Беларусь и стадия официального опубликования нормативных правовых актов: с 1 июля 2012 г. единственным источником официального опубликования правовых актов, зарегистрированных в НРПА, является Национальный правовой интернет-портал Республики Беларусь ${ }^{15}$.

Таким образом, НРПА, Национальный правовой интернет-портал Республики Беларусь, сайт «Правовой форум Беларуси» и другие являются стратегически важными для государства и общества информационно-правовыми ресурсами. Каждый из них формируется посредством соответствующей технологии, участниками которой являются различные государственные органы и организации. Полагаем, указанные информационные ресурсы можно считать программно-технологическими средствами правотворческой техники.

15 О некоторых вопросах опубликования и вступления в силу правовых актов Республики Беларусь : декрет Президента Республики Беларусь от 24 февраля 2012 г. № 3 // Национальный правовой интернет-портал Республики Беларусь. URL: http://pravo.by/document/?guid=3871\&p0=pd1200003 (дата обращения: 20.10.2019). 
Теория и история государства и права

Внутри средств правотворческой техники, используемых при выполнении иной работы, составляющей правотворческий процесс, можно выделить также подгруппу учетно-регистраиионных средств, которые необходимы для подтверждения фрактов получения нормативных правовых актов (из проектов), вручения, отправки, нахождения в канцелярии, архиве (штампы, надписи, регистрационные номера и т. д.).

Приемы правотворческой техники. Правотворческая техника имеет в своем арсенале различные приемы, причем они более динамичные, чем средства. Средства правотворческой техники если и дополняются, то, главным образом, за счет разрастания в современном обществе влияния информационных технологий и их внедрения во все сферы общества и государства. Приемы же более подвижны и за счет других факторов. Выбор использования того или иного приема правотворческой техники часто зависит от воли и сознания разработчика проекта, поскольку приемы являются определенными способами, действиями. А действия, в свою очередь, это «проявление какой-нибудь энергии, деятельности...»" ${ }^{16}$. В связи с этим полагаем, составление исчерпывающего перечня приемов правотворческой техники - задача весьма сложная. Развитие и совершенствование законодательства предполагают, кроме внедрения новых технологий, дополнение компонентов юридической техники, модернизацию образования специалистов, сталкивающихся с работой по подготовке правовых актов, и т. д.

Полагаем, основная доля приемов правотворческой техники применяется субъектами правотворчества для подготовки текста нормативных правовых актов. Указанные приемы можно разделить на два типа: 1) приемы изложения правовых норм в содержательном аспекте; 2) приемы изложения правовых норм в формальном аспекте.

Приелы изложения правовых норл в содержательнол аспекme. Как известно, одним из основных компонентов текста права, в том числе текста нормативного правового акта, является его структура, т. е. внутреннее устройство. Каждый нормативный правовой акт состоит из тех или иных структурных подразделений, имеющих соответствующее расположение и находящихся между собой в определенной логической связи. От того, насколько хорошо продумана структура акта, во многом зависит его доступность для восприятия.

Первичным структурным подразделением нормативного правового акта является статья (пункт). Именно в них нормы права находят свое реальное воплощение. В связи с этим можно говорить о первой подгруппе приемов - приель изложения правовой норлы в статье как структурной части нормативного правового акта. Речь об известной триаде - прялой, ссылочный, бланкетный приемы. Данная классификация приемов показывает характер изложения элементов юридической нормы. По С. С. Алексееву, при прямом изложении все элементы нормы прямо формулируются в данной статье нормативного акта. При блан-

\footnotetext{
${ }^{16}$ Ожегов С. Ю., Шведова Н. И. Указ. соч. С. 157.
} 


\section{Вестник ВГУ. Серия: Право}

кетном изложении отдельные элементы норм прямо не фрормулируются, но недостающие элементы выполняются не какой-либо точно указанной нормой, а правилами определенного вида, которые со временем могут изменяться. При ссылочном изложении отдельные элементы нормы не формулируются в данной статье; в ней делается отсылка к другой норме, где содержатся нужные предписания ${ }^{17}$.

Важно отметить, что статья нормативного правового акта не тождественна правовой норме. Как отмечает Н. В. Сильченко, «очень редко можно встретить примеры того, когда все три элемента логичной нормы права формулируются в тексте одной и той же статьи нормативного правового акта. Довольно часто встречаются примеры, когда в тексте одной и той же статьи излагается несколько норм права» ${ }^{18}$. В этом заключается главная сложность разработки нормативного правового акта: он, с одной стороны, должен быть компактным, а с другой - его предписания должны быть понятными и легко восприниматься. Нормативный правовой акт состоит не только из статей. В нем часто обозначаются положения, имеющие отношение ко всем последующим разделам, что позволяет избежать повторений. Поэтому важно вести речь о технико-юридических приемах создания правовых норм в целом.

Из вышеизложенного следует, что вторую подгруппу приемов изложения правовых норм в содержательном аспекте составляют приель изложения непосредственно правовых норл (вне зависимости от статьи или пункта).

Данные приемы также можно классифицировать. Во-первых, можно говорить о способах обобщения правовых норм, в частности об абстрактном и казуистическом приемах. Абстрактный (обобщающий) - такой прием формулирования юридических норм, при котором фактические данные охватываются обобщающей формулировкой, т. е. родовыми признаками. Казуистический прием юридической техники - это такой прием формулирования юридических норм, когда фактические данные указываются и при помощи индивидуальных признаков, в том числе путем перечисления конкретных, индивидуальных фрактов, обстоятельств ${ }^{19}$.

Во-вторых, можно выделить приемы, связанные с решениел содержательно-познавательных задач. В их числе приемы использования юридических (правовых) конструкций, классификаций, перечислений, определений, специальные приемы (правовые презумпции и фикции).

Так, с помощью юридических конструкиий (в литературе встречается также термин «правовые конструкции») логически связываются в единую систему правовые нормы со статьями нормативных правовых актов, и сам нормативный правовой акт приобретает четкость и определенность. Иными словами, юридическая конструкция дает возможность обобщить

${ }^{17}$ См.: Алексеев С. С. Общая теория права : в 2 т. Т. 2. С. 282-283.

${ }^{18}$ Сільчанка М. У., Сядзельнік В. В., Жаўняровіч С. А. Агульная тэорыя права : Навуч. Дапам / Пад. рэд. М. У. Сільчанкі. Гродна, 2004. С. 55.

${ }^{19}$ См.: Алексеев С. С. Общая теория права : в 2 т. Т. 2. С. 284. 
различные сложные правовые явления по их внутренней структуре, элементам, частям (состав правонарушения, юридическое лицо, стадии правоприменения, структура правовой нормы и др.) и служит также методом познания права и урегулированных им общественных отношений.

Классифбикация - прием, с помощью которого множество наблюдаемых явлений подразделяются на основные группы, классы, виды, входящие в общую систему и составляющие единое целое ${ }^{20}$. Данный прием важен и значим для конструирования правовых норм, поскольку позволяет выделить значимые отношения между однородными объектами (фактами, процессами), отнести (включить) конкретный объект в ту или иную группу классификации, а также разделить классифицируемые объекты. При этом содержательное значение данного приема правотворческой техники органично сочетается с доступной формой его внешнего выражения.

Перечисления (перечни) могут использоваться как необходимый элемент статьи (ее части, пункта), а также служить дополнением к нормативному правовому акту. Во втором случае перечни часто называют списками. Использовать данный прием правотворческой техники следует весьма осторожно, поскольку нормативный правовой акт должен содержать нормы понятные, максимально точные. Справедлив в своих утверждениях Д. А. Керимов: «...в тех случаях, когда нельзя обойтись без перечисления, следует добиваться, чтобы оно носило исчерпывающий характер ${ }^{21}$.

Одной из основных логических операций, позволяющей уточнить смысл правового предписания, являются определения. С помощью этого приема, как отмечает А. Нашиц, «понятия, являющиеся элементами правовой нормы, теми «кирпичиками», из которых она слагается, должны быть сформулированы наиболее точным образом» ${ }^{22}$. Использование определений встречается при построении кодифицированных актов и проявляется на уровне оформления (закрепления) различных структурных элементов нормы. В качестве примера можно привести требование, предъявляемое к гипотезе правовой нормы: «гипотеза может быть точной и строго определенной (например, в нормах уголовного права) или относительно определенной в других областях законодательства» ${ }^{23}$.

Среди приемов, связанных с решением содержательно-познавательных задач, определенное место занимают и так называемые специальные приелы, которые достаточно активно, но в то же время «осторожно» используются при создании нормативных правовых актов. Речь идет о применении правовых презулпиий и правовых фбикций. Под правовой

${ }^{20}$ См.: Баранов В. М., Кузнецов А. П., Маршакова Н. Н. Классификация в российском законодательстве (теоретико-прикладное исследование). М., 2014. С. 25.

21 Законодательная техника / под ред. Д. А. Керимова. Л., 1965. С. 51.

${ }^{22}$ Нашии А. Правотворчество. Теория и законодательная техника. М., 1974. C. 193.

${ }^{23}$ Там же. С. 198. 


\section{Вестник ВГУ. Серия: Право}

презумпцией понимается «предположение о наличии или отсутствии определенных фактов, основанных на связи между предполагаемыми фоктами и фрактами наличными, и подтвержденное предшествующим опытом»; под правовой фикцией - «включение несуществующих положений, признанных законодателем существующими и в силу этого общеобязательными» ${ }^{24}$. Классическим примером презумпции является презумпция невиновности, которая предусмотрена ст. 26 Конституции Республики Беларусь ${ }^{25}$. Пример фикции можно найти в уголовном праве: снятая или погашенная судимость признается несуществующей ${ }^{26}$. Полагаем, уровень научной разработанности вопросов, связанных с правовыми презумпциями и фикциями, в настоящее время невысок. Проблемы определения роли презумпций и фикций в праве, их логической природы, основных признаков и функций, а также состава этих понятий весьма объемны, значимы и заслуживают отдельного самостоятельного исследования. В настоящей статье мы обозначаем презумпции и фикции «специальными» приемами правотворческой техники.

Приелы изложения правовых норл в фборлальнол аспекте. Данный тип приемов менее разнообразен, поскольку, в первую очередь, направлен на упрощение восприятия текста нормативного правового акта за счет «внешнего выражения».

Среди приемов правотворческой техники рассматриваемого типа можно говорить о делении нормативного правового акта на раздель, главbl, статьи, параграфбы, пункты и $m$. д. Структуризация нормативных правовых актов различна, поскольку обусловлена их содержанием. Кроме того, имеется практика деления нормативных правовых актов на чаcmu. Данный прием давно используется в правотворческой практике и касается, в первую очередь, подготовки кодексов.

Использование примечаний - это вспомогательный прием правотвор-

으 ческой техники, который используется при оформлении содержания нестандартного, дополнительного материала и может содержать схемы, таблицы, перечни, графики и т. д. Особенность примечаний в том, что они не носят обязательного характера и могут применяться по усмотрению разработчика нормативного правового акта. В. М. Баранов и

106 Д. С. Кондаков полагают, что примечания необходимы для «специального содержательного текстового либо символического подчеркивания, обособления какого-либо факта, обстоятельства, состояния, фрагмента

${ }^{24}$ Каргин К. В. Юридические документы / науч. ред. В. А. Толстик. М., 2008. C. 153.

${ }^{25}$ Конституция Республики Беларусь : закон Республики Беларусь от 15 марта 1994 г. № 2875-XII с изм. и доп., принятыми на респ. референдумах 24 ноября 1996 г. и 17 октября 2004 г. // ЭТАЛОН. Законодательство Республики Беларусь / Нац. центр правовой информ. Респ. Беларусь. Минск, 2019.

${ }^{26}$ См.: Лызлов Д. Н., Картухин В. Ю. Юридическая техника : учеб. пособие. M., 2009. C. 38. 
деятельности, процесса» ${ }^{27}$. В связи с этим можно полагать, что прием использования примечаний следует рассматривать как прием, влияющий на содержательную сторону нормативного правового акта. Однако, на наш взгляд, при создании нормативного правового акта следует добиваться компактности, краткости нормативного акта, его «внешней легкости». Если использование примечаний перегружает документ излишней информацией, то лучше отказаться от использования данного приема. Отсюда - наше отнесение примечаний к приемам изложения правового материала в формальном аспекте.

Поправки как отдельный прием правотворческой техники используются для дополнения или изменения положений нормативного правового акта. Как отмечает К. В. Каргин, «необходимость внесения поправок возникает в связи с недостаточной ясностью юридического документа, с наличием в нем двусмысленных положений, которые могут привести к юридическим конфликтам, или, наоборот, отсутствием положений, закрепление которых придало бы четкость в правовом регулировании» ${ }^{28}$. Как правило, поправки вносятся нормативным правовым актом, соответствующим по статусу тому, в который вносятся изменения или дополнения. Данный прием правотворческой техники отличается от иных приемов своей целью - совершенствование уже созданного нормативного правового акта. Кроме того, при использовании приема внесения поправок могут быть использованы и иные, содержательные, приемы правотворческой техники, о которых шла речь выше (юридические конструкции, классификации и т. д.).

Итак, средства правотворческой техники делятся на два типа. Первый тип средств правотворческой техники - средства, используелье при создании текста проекта норлативного правового акта. Все средства данного типа делятся на три самостоятельные подгруппы: а) формальные (реквизиты нормативного правового акта и др.); б) содержательные (выражены во всем многообразии языковых средств, стиля, понятий, особой терминологии и т. д.); в) технические (инструментальные) (компьютеры, программное обеспечение, офисная техника, бумага и т. д.). Второй тип - средства, используемые при выполнении иной работы, составляющей правотворческий процесс. Указанные средства делятся на две подгруппы: а) программно-технологические (государственные информационные ресурсы; информационные ресурсы сети «Интернет»; автоматизированные системы и т. д.); б) учетно-регистрационные (штампы, надписи и т. д.) и др.

Приемы правотворческой техники также делятся на два типа. Первый тип - приелы изложения правовых норл в содержательном аспекme. Одну из подгрупп приемов этого типа составляют приемы, использу-

${ }^{27}$ Баранов В. М., Кондаков Д. С. Примечания в российском праве : природа, виды, проблемы реализации // Проблемы юридической техники : сб. статей / под ред. В. М. Баранова. Н. Новгород, 2000. С. 342-343.

${ }^{28}$ Каргин К. В. Указ. соч. С. 156. 


\section{Вестник ВГУ. Серия: Право}

емые для изложения правовой нормы в статье нормативного правового акта, - прямой, ссылочный, бланкетный. Другая подгруппа приемов включает приемы изложения непосредственно правовых норм: а) по степени обобщения (абстрактный, казуистический); б) связанные с решением содержательно-познавательных задач (использование юридических конструкций; классификаций; перечислений; определений и др.); в) специальные приемы - правовые презумпции, правовые фрикции и др. Второй тип приемов правотворческой техники - приелы изложения правовых норл в фбормальнол аспекте (деление нормативного правового акта на части, разделы, главы, статьи, параграфы, пункты; использование примечаний, поправок, сносок и др.).

Национальный иентр законодательства и правовых исследований Республики Беларусь

Швед Е. Н., аспирант Института правовых исследований

E-mail: shved_en@mail.ru
National Center Legislation and Legal Research of the Republic of Belarus

Shved E. N., Post-graduate Student of the Institute of Legal Studies

E-mail: shved_en@mail.ru 